\title{
A novel surfactant-assisted dilute phosphoric acid plus steam explosion pretreatment of poplar wood for fermentable sugar production
}

\section{Denghui Tong}

Central South University of Forestry and Technology https://orcid.org/0000-0002-6349-375X

\section{Peng Zhan}

Central South University of Forestry and Technology

\section{Weifeng Zhang}

Central South University of Forestry and Technology

\section{Yongcai Zhou}

Central South University of Forestry and Technology

\section{Yilei Huang}

Central South University of Forestry and Technology

\section{Yan Qing}

Central South University of Forestry and Technology

Jienan Chen ( $\nabla$ chenjnx@163.com )

Central South University of Forestry and Technology

\section{Research Article}

Keywords: Steam explosion pretreatment, Dilute phosphoric acid, Surfactant, Enzymatic saccharification, Poplar

Posted Date: August 31st, 2021

DOI: https://doi.org/10.21203/rs.3.rs-836994/v1

License: (a) (1) This work is licensed under a Creative Commons Attribution 4.0 International License. Read Full License 


\section{Abstract}

Pretreatment is an indispensable process in lignocellulosic bioethanol production. In this work, a surfactant agent JFC was introduced into the dilute phosphoric acid plus steam explosion pretreatment scheme for fermentable sugar production using poplar as substrate. Four crucial factors (phosphoric acid concentration, surfactant concentration, pressure, and residence time) affecting the pretreatment efficiency were optimized using the single factor tests. The optimal parameters obtained were as follows: 1:2.5 solid/liquid rate, $2 \mathrm{~h}$ pre-soaking time, $1.5 \%(\mathrm{v} / \mathrm{v}) \mathrm{JFC}-\mathrm{M}+2.0 \mathrm{wt} \%$ phosphoric acid, $2.0 \mathrm{MPa}$ pressure, and $120 \mathrm{~s}$ residence time, resulting in a maximum cellulose recovery rate of $86.33 \%$ and enzymatic saccharification rate of $84.62 \%$, which was $38.97 \%$ higher than that of control. The morphological and structural characteristics of samples before and after pretreatment, were characterized by the scanning electron microscopy (SEM), X-ray diffraction (XRD), and Fourier transform infrared (FTIR) method. The addition of JFC-M was of a notable influence in overcoming biomass recalcitrance and boosting cellulose digestion, showing great application potentials in biomass conversion process.

\section{Introduction}

Lignocellulosic biomass (LCB) is the most abundant and renewable resource on the planet, which can act a low-cost and promising feedstock for production biofuels, biomaterials, and biochemicals, etc., attracting worldwide interests and attentions (Alonso et al. 2017). However, owing to the high biomass recalcitrance, a suitable pretreatment process is required to remove lignin and hemicellulose, depolymerize of cellulose of LCB, and release fermentable sugars for further bioconversion such as bioethanol production (Qi et al. 2018; Tu and Hallett 2019).

To date, several LCB pretreatment techniques have been developed, which are mainly categorized into physical, chemical, physicochemical, biological techniques, and some cocktail of these strategies (Haldar and Purkait 2020). Among them, steam explosion (SE) method is of advantages such as cost-effective and environmentally -friendly supermolecular deconstruction, which is widely applied in LCB especially hardwood and agricultural residual pretreatment (Jacquet et al. 2015). Meanwhile, to improve the efficiency and reduce the severity of SE (e.g., lowering the temperature and pressure, shortening the residence time), some chemical additives, mainly mineral acids or alkalis (such as $\mathrm{SO}_{2}, \mathrm{H}_{2} \mathrm{SO}_{4}, \mathrm{H}_{3} \mathrm{PO}_{4}$, and $\mathrm{NH}_{4}$ ), are introduced into SE process (Zhang et al. 2020).

Dilute phosphoric acid plus steam explosion (DPASE) is a promising alternative LCB pretreatment method (Fockink et al. 2018; Geddes et al. 2011; Oliva et al. 2020), holding the advantages as following: (i) acting as an exogenous weak acid catalyst, dilute $\mathrm{H}_{3} \mathrm{PO}_{4}$ results in low sugar loss and yield of toxins simultaneous with SE (Pitarelo et al. 2016; Zeng et al. 2014); (ii) $\mathrm{H}_{3} \mathrm{PO}_{4}$ can not only serve as an additional source of nutrients for microbe, but can also be partly recovered and reused as a fertilizer (Geddes et al. 2011); and (iii) $\mathrm{H}_{3} \mathrm{PO}_{4}$ is less corrosive to the SE apparatus, which is beneficial for the equipment and efforts at scaling up (Haykiri-Acma and Yaman 2019; Koradiya et al. 2016). However, 
regarding the distinct components and microstructures of multisourced LCB feedstocks (e.g., dedicated crops, agricultural residues, and short-rotation energy coppices), more researches are needed to expand the application of DPASE.

It has been reported that surfactants, particularly nonionic surfactants (Tween, Triton, and polyethylene glycol, etc.) in the pretreatment process can promote the wettability of LCB, decrease the crystallinity of cellulose, give higher cellulose conversion, improve the delignification rate, maximize the enzymatic convertibility, and enhance the ethanol yields, etc. (Cao and Aita 2013; Jørgensen et al. 2007; Nasirpour et al. 2014; Zheng et al. 2020). A fatty alcohol polyoxyethylene ether based nonionic surfactant agent JFC ( $\mathrm{R}-\mathrm{O}\left(\mathrm{CH}_{2} \mathrm{CH}_{2} \mathrm{O}\right)_{5}-\mathrm{H}$, wherein $\left.\mathrm{R}=\mathrm{C}_{7-9}\right)$, holds the properties of reducing interfacial tension, enhancing the wettability of materials, improving the capillary effect inside fibers, etc., which has been introduced in textile modification (Gao et al. 2017), coal mining (Shi et al. 2019), porous geopolymers preparation (Yan et al. 2021), mineral flotation (Chen et al. 2018), etc. Considering its other advantages such as strong acid, alkali, and high temperature resistance and no bio-toxicity, the surfactant agent JFC holds potential of assisting the LCB steam explosion pretreatment.

In this work, a novel surfactant JFC-assisted dilute phosphoric acid plus steam explosion pretreatment of poplar wood craft was developed. Four crucial factors (phosphoric acid concentration, surfactant concentration, pressure, and residence time) affecting the pretreatment efficiency were optimized using the single factor tests. The morphological and structural characteristics of samples were characterized for analyzing the mechanism of pretreatment and further optimizing of the process.

\section{Materials And Methods}

\subsection{Materials}

The dried European black poplar (Populus nigra L.) chips were pulverized by a plant shredder to sawdust (1-2 mm diameter, 2-15 mm length) as feedstocks. The surfactant JFC-M (industrial grade) was purchased from Shandong Yousuo Chemical Technology Co., Ltd. (Zhou et al. 1995). The cellulase was purchased from Qingdao Vland Biotech INC.(Qingdao, China), holding a filter paper activity (FPA) of 191 $\mathrm{IU} / \mathrm{mL}$. The chemical agents like phosphoric acid, sulfuric acid, and calcium carbonate, etc., were analytical grade and could be used without further purification.

\subsection{Experimental method 2.2.1 DPASE}

The poplar sawdust was presoaked in a JFC-M and dilute $\mathrm{H}_{3} \mathrm{PO}_{4}$ solution at 1:2.5 solid/liquid rate for $2 \mathrm{~h}$, and then pretreated in a SE apparatus QBS-80B (Tsing Gentle Eco-technology (Suzhou) Co., Ltd.) equipped a $400 \mathrm{~mL}$ cylinder. The exploded slurry was collected for further study. For detection the removal of cellulose and hemicellulose after DPASE, the exploded slurry was separated by a centrifuge at $1000 \mathrm{r} / \mathrm{min}$ and the filtrate was collected for further analysis. 


\subsubsection{Single factor experiment}

The single factor experiment was conducted using four critical factors influencing the pretreatment efficiency such as surfactant JFC-M and $\mathrm{H}_{3} \mathrm{PO}_{4}$ concentration, pressure of explosion, and residence time.

\subsubsection{Enzymatic saccharification}

The exploded slurry was dried in a drying oven (Tianjin Taisite Instrument Co., Ltd.) at $60^{\circ} \mathrm{C}$ for $48 \mathrm{~h}$ and then added into $100 \mathrm{~mL}$ Erlenmeyer flasks containing $50 \mathrm{~mL}$ citric acid buffer and with 1:50 solid/liquid rate. The enzymatic saccharification was carried out with parameters as following: $30 \mathrm{lU} / \mathrm{g}$ dry exploded slurry cellulase loading, $180 \mathrm{rpm} / \mathrm{min}$ stirring speed, initial solution $\mathrm{pH} 4.8,50^{\circ} \mathrm{C}$ reaction temperature for $72 \mathrm{~h}$.

The saccharification rate is calculated as follows (Kim 2011):

$$
\text { Saccharification Rate }(\%)=\frac{C 0 \times V \times 0.9}{\left(C_{1}+C_{2}\right) \times M} \times 100 \%
$$

Wherein, $C_{0}$ is the concentration of reducing sugar (RS) in the hydrolysate. $V$ is the volume of hydrolysate. $C_{1}$ and $C_{2}$ are the cellulose and hemicellulose contents in the substrate after pretreatment. $M$ is the dry mass of the substrate, and " 0.9 " means that $1.0 \mathrm{~g}$ RS is equivalent to the mass of $0.9 \mathrm{~g}$ cellulose and hemicellulose.

\subsubsection{Composition analysis}

The cellulose, hemicellulose and lignin of samples were analyzed according the national renewable energy laboratory (NREL) standard method (Sluiter et al. 2008).

The solid and cellulose recovery rate (or retention rate) is calculated as follows:

Solid or cellulose recovery $(\%)=\frac{m_{2}}{m_{1}} \times 100 \%$

Wherein, $m_{1}$ and $m_{2}$ are the masses of poplar substrate or cellulose before and after pretreatment, respectively.

The hemicellulose removal rate is calculated as follows:

Hemicellulose recovery $(\%)=\left(1-\frac{m_{2}}{m_{1}}\right) \times 100 \%$

Wherein, $m_{1}$ and $m_{2}$ are the masses of hemicellulose before and after pretreatment, respectively. 
The concentration of RS was determined by a high-performance liquid chromatography (HPLC,

Thermofisher U3000, Thermo Fisher Scientific) with a chromatographic column Aminex HPX-87H according the NREL standard method (Sluiter et al. 2008). The analysis conditions were as follows: 5 $\mathrm{mmol} / \mathrm{L} \mathrm{H}_{2} \mathrm{SO}_{4}$ mobile phase, $45^{\circ} \mathrm{C}$ column temperature, $5 \mathrm{~mL} / \mathrm{min}$ flow rate, $30^{\circ} \mathrm{C}$ differential refractive index temperature, and $20 \mu \mathrm{l}$ sample volume. All tested samples were filtered by a $0.22 \mu \mathrm{m}$ filter membrane. The standard sugar gradient solution was prepared with cellobiose, glucose, xylose, and arabinose, and the standard curve was drawn by the external standard method.

\subsubsection{Structure characterization}

The samples before and after pretreatment were dried in a constant-temperature drying oven at $105^{\circ} \mathrm{C}$ to a constant weight for further structure characterization. The SEM was carried out by a Zeiss Sigma 300 scanning electronic microscope. The cellulose crystallinity of samples were analyzed by an X-ray diffraction analyzer (X'Pert PRO, PANalytical, Netherlands), with the following parameters: $0.15406 \mathrm{~nm}$ wavelength, $45 \mathrm{kV}$ voltage, $40 \mathrm{~mA}$ current, $5^{\circ}-50^{\circ}$ scanning angle $2 \theta$ range, and $5^{\circ} / \mathrm{min}$ scanning rate.

The crystallinity is calculated as follows (Segal et al. 1959):

$$
C I(\%)=\frac{I_{002}-I_{a m}}{I_{002}} \times 100 \%
$$

Wherein, $I_{002}$ represents the maximum intensity of the crystalline part at $22^{\circ}$, and $I_{\text {am }}$ represents the minimum intensity of the non-crystalline part at $18^{\circ}$.

The Fourier transform infrared (FTIR) analysis was conducted by an IRAffinity-1S spectrometer (Shimadzu Corp., Kyoto, Japan) with following parameters: $400-4000 \mathrm{~cm}^{-1}$ wave number, 32 scans per second analysis speed, and $4 \mathrm{~cm}^{-1}$ resolution ratio, respectively.

\section{Results And Discussion}

\subsection{Effect of phosphoric acid on pretreatment}

Generally, the content of glucose and xylose in exploded filtrate reflects the removal of cellulose and hemicellulose, respectively. As shown in Fig. $1 \mathrm{a}$, the content of glucose in exploded filtrate increased when the $\mathrm{H}_{3} \mathrm{PO}_{4}$ was less than $2.0 \mathrm{wt} \%$, and then decreased slightly with the increase of $\mathrm{H}_{3} \mathrm{PO}_{4}$, holding a maximum value of $3.61 \mathrm{~g} / \mathrm{L}$, which was 3.4 times that in the blank group. The content of xylose in exploded filtrate increased with the increase of $\mathrm{H}_{3} \mathrm{PO}_{4}$, holding a maximum value of $8.79 \mathrm{~g} / \mathrm{L}$ at $2.5 \mathrm{wt} \%$ $\mathrm{H}_{3} \mathrm{PO}_{4}$, which was 2.5 times that in the blank group. The higher titter of xylose yielded compared with that of glucose could be attributed to two reasons: (i) xylan is more labile than glucan in LCB substrate (Chen et al. 2007); (ii) the exogenous $\mathrm{H}_{3} \mathrm{PO}_{4}$ catalyst presents higher capacity of solubilizing hemicellulose of LCB (Oliva et al. 2020). According to Fig. 1b, the saccharification rates of samples were positively 
correlated with the $\mathrm{H}_{3} \mathrm{PO}_{4}$ concentrations, holding a maximum value of $78.52 \%$ at $2.5 \mathrm{wt} \% \mathrm{H}_{3} \mathrm{PO}_{4}$, which was $27.95 \%$ higher than that in the blank group. The removal of hemicellulose increased the internal porosity of the fiber and provided more enzyme contact sites, boosting the enzymatic saccharification of substrate (Leu and Zhu 2013). The addition of surfactant JFC-M helps to remove hemicellulose and increase the enzymatic saccharification rate. Considering the cost-effectiveness of pretreatment, $2.0 \mathrm{wt} \%$ $\mathrm{H}_{3} \mathrm{PO}_{4}$ was used for further study.

\subsection{Effect of surfactant JFC-M on pretreatment}

As shown in Fig. 2a, the content of glucose in exploded filtrate increased when the JFC-M concentration was less than $1.0 \%(\mathrm{v} / \mathrm{v})$, and then decreased slightly with the increase of JFC-M, holding a maximum value of $3.28 \mathrm{~g} / \mathrm{L}$, which was 3.3 times that in the blank group. The content of xylose in exploded filtrate increased when the JFC-M concentration was less than $1.5 \%(\mathrm{v} / \mathrm{v})$, and then decreased with the increase of JFC-M, holding a maximum value of $8.56 \mathrm{~g} / \mathrm{L}$, which was 2.5 times that in the blank group. When the JFC-M concentration was less than $2.0 \%(\mathrm{v} / \mathrm{v})$, the saccharification rate of samples increased with the increase of JFC-M, and then decreased, holding a maximum value of $80.91 \%$ at $2.0 \%(\mathrm{~V} / \mathrm{v}) \mathrm{JFC}-\mathrm{M}$, which was $20.02 \%$ higher than that in the blank group (Fig. 2b). The decreased of saccharification rate with the increase of JFC-M might be caused by the negative effect of surfactant and inhibitors generated in the pretreatment process, which should be done further research.The reasons for this may be as follows (Kim 2011; Leu and Zhu 2013; Li et al. 2014): (i) the addition of surfactant JFC-M increased the surface area and porosity of poplar fiber; (ii) alleviation the adhesion of pseudo-lignin to the fiber surface after explosion, and reduced the ineffective adsorption of cellulase on the surface of lignin; (iii) improvement the stability of cellulase activity; and (iv) changes of the substrate structures to further promote enzymatic hydrolysis. Considering the cost-effectiveness of pretreatment, $1.5 \%(\mathrm{v} / \mathrm{v})$ surfactant JFC-M was used for further study.

\subsection{Effect of pressure on pretreatment}

The contents of glucose and xylose increased with the increase of SE pressure, holding maximum values of $3.48 \mathrm{~g} / \mathrm{L}$ and $8.73 \mathrm{~g} / \mathrm{L}$, respectively (Fig. 3a). The saccharification rates of samples increased with the increase of SE pressure, holding a maximum value of $82.96 \%$ at $2.4 \mathrm{MPa}$ SE pressure, which was 22.07 $\%$ higher than that in the blank group (Fig. $3 b$ ). Pressure is correlated to temperature and has impacts on hemicellulose degradation to soluble mono- and oligosaccharides, and cleavage of lignin carbohydrate complex (Chen and Qiu 2010). The recently study revealed that with the increase of pressure, the inhibitors generated in SE process using poplar as a feedstock basically maintained at the same level (Wang et al. 2020). Considering the increase of pressure would increase the energy consumption, 2.0 MPa SE pressure was used for further study.

\subsection{Effect of residence time on pretreatment}

The content of glucose in exploded filtrate increased when the residence time was less than $180 \mathrm{~s}$, and then decreased slightly, holding a maximum value of $3.03 \mathrm{~g} / \mathrm{L}$, which was 2.8 times that in the blank group (Fig. 4a). The content of xylose in exploded filtrate increased with residence time, holding a 
maximum value of $8.70 \mathrm{~g} / \mathrm{L}$ at residence time of $300 \mathrm{~s}$, which was 2.5 times that in the blank group. As shown in Fig. 4b, when the residence time was less than $120 \mathrm{~s}$, the saccharification rates of samples increased with the increase of JFC-M, and then decreased, holding a maximum value of $84.62 \%$ at residence time of $120 \mathrm{~s}$, which was $23.73 \%$ higher than that in the blank group. The hydrolysis of hemicellulose is closely correlated to the residence time of SE, and a high residence time allows the complete hydrolysis of hemicellulose and decrease the solid recovery (Jacquet et al. 2015). The drops of saccharification rate, when the residence time was over $120 \mathrm{~s}$, might be the reason that part of the xylose or glucose are converted into enzymolysis inhibitors, which adversely inhibits the enzymatic hydrolysis (Junhua Zhang et al. 2012). Considering the saccharification rate of poplar, 120 s residence time was selected. In summary, a maximum saccharification rate was obtained under the DPASE parameters as follows: 1:2.5 solid/liquid rate, $2 \mathrm{~h}$ pre-soaking time, $1.5(\mathrm{v} / \mathrm{v}) \% \mathrm{JFC}-\mathrm{M}+2.0 \mathrm{wt} \% \mathrm{H}_{3} \mathrm{PO}_{4}, 2.0 \mathrm{MPa} \mathrm{SE}$ pressure, and $120 \mathrm{~s}$ residence time.

\subsection{Components change of samples}

The components of samples before and after pretreatment are shown in Table 1.

The contents of cellulose and lignin in DPASE (55.61 \% and $31.05 \%)$ and JFC-M + DPASE $(64.80 \%$ and $33.10 \%$ ) group were greater than that of the raw material (44.58 \% and $28.32 \%)$, respectively. The content of hemicellulose in the two pretreatment groups $(6.05 \%$ and $2.97 \%)$ decreased dramatically compared with that of the aw material $(12.05 \%)$. As the assistant removal of hemicellulose and lignin using a surfactant (Qing et al. 2010), the solid recovery rate in JFC-M + DPASE (55.97 \%) group was lower than the one in DPASE group (73.12 \%). The hemicellulose removal rate in JFC-M + DPASE (83.50 \%) group was higher than the one in DPASE group (60.47\%). Comparing the results reported in Table 2, the addition of surfactant JFC-M increased the removal of hemicellulose, leading to a relatively high cellulose recovery rate obtained. Considering the SE conditions, sugars resolved in exploded filtrate, recovery rates, and saccharification rate, the surfactant-assisted DPASE pretreatment method performs advantages over other SE method 
Table 1

Compositions (\%), recovery and removal rates (\%) of samples*.

\begin{tabular}{|llll|}
\hline Component (\%) & Raw & DPASE & JFC-M + DPASE \\
\hline Carbohydrate & 56.63 & 55.61 & 64.80 \\
\hline Cellulose & 44.58 & 49.56 & 61.83 \\
\hline Hemicellulose & 12.05 & 6.05 & 2.97 \\
\hline Lignin & 28.32 & 31.05 & 33.10 \\
\hline Acid-soluble lignin & 1.54 & 1.36 & 1.29 \\
\hline Acid-insoluble lignin & 26.78 & 29.69 & 31.81 \\
\hline Solid recovery rate & $/$ & 73.12 & 55.97 \\
\hline Cellulose recovery rate & $/$ & 88.85 & 86.33 \\
\hline Hemicellulose removal rate & $/$ & 60.47 & 83.50 \\
\hline * Note: (1) the alcohol extract and ash of raw poplar feedstock is $1.68 \%$ and $0.84 \%$, respectively. (2) \\
\hline All the samples were analyzed according the NREL standard method. \\
\hline
\end{tabular}


Table 2

Compositions (\%) and recovery rates (\%) of samples in literature*.

\begin{tabular}{|c|c|c|c|c|}
\hline SE Conditions & $\begin{array}{l}\text { Composition } \\
\text { (\%) }\end{array}$ & $\begin{array}{l}\text { Sugars in } \\
\text { filtrate(\%) }\end{array}$ & $\begin{array}{l}\text { Recovery } \\
\text { (\%) }\end{array}$ & Reference \\
\hline $\begin{array}{l}1-2 \times 2-15 \mathrm{~mm} \text { particle size, } 1: 2.5 \\
\text { solid/liquid rate, } 2 \mathrm{~h} \text { pre-soaking time, } 1.5 \\
(\mathrm{v} / \mathrm{v}) \% \mathrm{JFC}-\mathrm{M}+2.0 \mathrm{wt} \% \mathrm{H}_{3} \mathrm{PO}_{4}, 2.0 \mathrm{MPa} \\
\text { pressure, } 120 \text { s residence time. }\end{array}$ & $\begin{array}{l}44.58 \% \mathrm{C} \\
12.05 \% \mathrm{H} \\
28.32 \% \mathrm{~L} .\end{array}$ & $\begin{array}{l}1.56- \\
3.41 \% \\
\text { glucose, } \\
2.15- \\
8.79 \% \\
\text { Xylose. }\end{array}$ & $\begin{array}{l}86.33- \\
88.85 \% \\
\text { C. } \\
55.97- \\
73.12 \% \\
\text { SR. }\end{array}$ & this work \\
\hline $\begin{array}{l}30 \times 30 \times 5 \mathrm{~mm} \text { particle size, } \mathrm{N}_{2} \text { added in } \mathrm{SE} \\
\text { process, } 209 \pm 0.5^{\circ} \mathrm{C}, 7 \mathrm{~min} \text { residence time. }\end{array}$ & $\begin{array}{l}44.1 \% \mathrm{C} \\
19.4 \% \mathrm{H} \\
27.8 \% \mathrm{~L} .\end{array}$ & $\begin{array}{l}1.35- \\
1.39 \% \\
\text { glucose, } \\
7.36- \\
8.14 \% \\
\text { xylose. }\end{array}$ & $\begin{array}{l}55.1- \\
56.2 \% \mathrm{C}, \\
4.9-5.6 \\
\% \mathrm{H}, \\
19.5- \\
20.8 \% \mathrm{~L}, \\
59.5- \\
65.0 \mathrm{SR} .\end{array}$ & $\begin{array}{l}\text { Wang et } \\
\text { al. (2020) }\end{array}$ \\
\hline $\begin{array}{l}10( \pm 2) \mathrm{mm} \text { particle size, } 200 \text { or } 220^{\circ} \mathrm{C}, 5 \mathrm{~min} \\
\text { residence time. }\end{array}$ & $\begin{array}{l}35.5-40.4 \% \\
\text { C, } 18.1-22.9 \\
\% \text { H, } \\
30.1-38.2 \% \\
\text { L. }\end{array}$ & $\begin{array}{l}1.3-1.9 \\
\% \\
\text { glucose, } \\
6.4-9.8 \\
\% \text { xylose. }\end{array}$ & $\begin{array}{l}32.0- \\
40.0 \\
\text { acid- } \\
\text { insoluble } \\
\text { lignin, } \\
62.8- \\
76.5 \mathrm{SR} .\end{array}$ & $\begin{array}{l}\text { Martín- } \\
\text { Davison } \\
\text { et al. } \\
(2015)\end{array}$ \\
\hline $\begin{array}{l}30 \times 15 \times 5 \mathrm{~mm} \text { size, } 190-220^{\circ} \mathrm{C}, 7-11 \mathrm{~min} \\
\text { residence time. }\end{array}$ & $\begin{array}{l}44.3 \% \mathrm{C} \\
16.2 \% \mathrm{H} \\
26.9 \% \mathrm{~L} .\end{array}$ & / & $\begin{array}{l}62.8- \\
76.5 \mathrm{SR}\end{array}$ & $\begin{array}{l}\text { Castro et } \\
\text { al. (2014) }\end{array}$ \\
\hline $\begin{array}{l}2.5 \times 2.5 \mathrm{~cm} \text { and } 5.0 \times 5.0 \mathrm{~cm} \text { size, Alkaline- } \\
\text { oxygen impregnated SE: } 12 \mathrm{wt} \% \mathrm{Na}_{2} \mathrm{CO}_{3} \\
100-110^{\circ} \mathrm{C}, 100 \text { psig } \mathrm{O}_{2}, 135^{\circ} \mathrm{C}, 3 \mathrm{~min} ; \mathrm{SE}: \\
210^{\circ} \mathrm{C}, 10 \mathrm{~min} \text { residence time. }\end{array}$ & $\begin{array}{l}45.7 \% \mathrm{C} \\
17.4 \% \mathrm{H} \\
34.9 \% \mathrm{~L}\end{array}$ & I & $\begin{array}{l}94-97 \% \\
\text { C, } \\
54-71 \% \\
\text { H. }\end{array}$ & $\begin{array}{l}\text { Chu et al. } \\
\text { (2017) }\end{array}$ \\
\hline
\end{tabular}

* Note:(1) C, H, L, and SR represents cellulose, hemicellulose, lignin, and solid recovery, respectively.

(2) All the samples were analyzed according the NREL standard method.

\section{Characterization Of Samples}

\subsection{SEM analysis}


The morphological changes of samples were characterized by the SEM method, and the results were shown in Fig. 5. The raw poplar is of tightly packed and dense structure with the smooth surface morphology (Fig. 5a,b). In DPASE group (Fig. 5c,d), some slight damages occurred at the surface and interior of poplar fiber. The uneven spherical precipitates were formed on the surface of fiber, which is probably the result of the formation of lignin microspheres or pseudo-lignin microspheres at high temperatures (Cheng et al. 2018). In JFC-M + DPASE group (Fig. 5e,f), severe damages were occurred, performing densely wrapped and broken structures of fiber, which greatly increased the specific surface area and porosity of the feedstock and was beneficial for subsequent enzymatic saccharification. The surfactant JFC-M may have a unique mode of action in assisting of the DPASE process by the means of following. Firstly, JFC-M promotes the wetting of the surface of poplar fiber by $\mathrm{H}_{3} \mathrm{PO}_{4}$ solution and permeation into the interior of the fibers, so as to improve the acid-catalyzed deconstruction of poplar fiber. The results were in line with literature reported that the addition of surfactants quite better option for acid pretreatment (Singh et al. 2015).

\subsection{XRD analysis}

Crystallinity of LCB is a crucial factor that influences the enzymatic hydrolysis. The crystallinity index (Crl) of samples are determined by the XRD analyse and the results are shown in Fig. 6. The relative crystallinities of DPASE (62.09 \%) and JFC-M + DPASE (63.42 \%) pretreated samples were greater than that of the unpretreated poplar(53.59\%), which was consist with the results of previous studies (Singh et al. 2015). The increase of crystallinity was mainly caused by the deconstruction of crystalline area of cellulose, removal of hemicellulose and delignification (Jacquet et al. 2015). Once the crystalline areas become small and amorphous, the accessibility of enzyme to the cellulose substrate could be improved. The higher crystallinity of JFC-M + DPASE pretreated sample than that of the DPASE is in line with the results of the single factor test and changes of components. After enzymatic hydrolysis, the $\mathrm{Crl}(46.72 \%)$ of sample decreased, which might be caused by some destroy of the crystalline area of cellulose during the enzymatic hydrolysis process, resulting in the loose and irregularly arranged area becoming into the amorphous area.

\subsection{FTIR analysis}

The structural modifications of samples were identified by a FTIR analysis and the results were shown in Fig. 7. The enhancements of $\mathrm{C}-\mathrm{H}$ and $-\mathrm{OH}$ stretching vibrations $\left(3423 \mathrm{~cm}^{-1}-2924 \mathrm{~cm}^{-1}\right)$ of cellulose after pretreatment (Wang et al. 2020), indicates more loose cellulose are obtained for the subsequent enzymatic hydrolysis process, especially in the JFC-M added group, which is consistent with the results of SEM. The characteristic absorption peak of hemicellulose xylan $\left(1740 \mathrm{~cm}^{-1}\right)(B u$ et al. 2011), decreases after pretreatment, especially in the JFC-M + DPASE group, indicating that the addition of surfactant is more conducive to removing hemicellulose. Here, $1510 \sim \mathrm{cm}^{-1}$ is the $\mathrm{C}=\mathrm{C}$ stretching vibration of the pure lignin aromatic ring in LCB (Anderson et al. 1991). The $\mathrm{C}-\mathrm{H}$ and $\mathrm{C}-\mathrm{O}$ stretching vibration of the syringyl benzene ring in the lignin is noted at $1120 \mathrm{~cm}^{-1}$ (Schwanninger et al. 2004). All samples after pretreatment show absorption at $1120 \mathrm{~cm}^{-1}$, indicating the existing of syringyl lignin in 
poplar wood. The stretching vibration at $898 \mathrm{~cm}^{-1}$ is the characteristic peak of $\beta$-glycosidic bond (Ibrahim et al. 2010), the intensity of which dropped slightly after pretreatment, indicating that a small amount of glucan is degraded during the pretreatment process. This is consistent with the glucose content in exploded filtrate after pretreatment.

\section{Conclusions}

In this study, a surfactant JFC-M assisted dilute phosphoric acid plus steam explosion pretreatment of poplar wood was developed. Four crucial factors such as phosphoric acid concentration, surfactant concentration, pressure, and residence time were optimized using the single factor tests. The results showed under the optimized conditions: 1:2.5 solid/liquid rate, $2 \mathrm{~h}$ pre-soaking time, $1.5(\mathrm{v} / \mathrm{v}) \% \mathrm{JFC}-\mathrm{M}+$ $2.0 \mathrm{wt} \%$ phosphoric acid, $2.0 \mathrm{MPa}$ pressure, and $120 \mathrm{~s}$ residence time, a $86.33 \%$ cellulose recovery rate and $84.62 \%$ enzymatic saccharification rate were obtained. The surfactant JFC-M increased the removal of hemicellulose and a high cellulose recovery rate, which in turn booted the enzymatic saccharification of substrate. The morphological and structural characteristics of samples were analyzed for revealing the mechanism of pretreatment and further optimizing of the process. The novel pretreatment process shows great application potentials in biomass conversion process.

\section{Declarations}

\section{Acknowledgments}

The authors are grateful for the support provided by the National Key Research and Development Program of China (Grant No. 2019YFB1503801) and the Key Research and Development Program of Hunan Province (Grant No. 2020WK2019, 2019CB1002).

\section{interest statement}

There are no conflicts of interest to declare.

\section{Data availability statement}

The datasets generated during and/or analysed during the current study are available from the corresponding author on reasonable request.

\section{References}

1. Alonso DM, Hakim SH, Zhou S, Won W, Hosseinaei O, Tao J, Garcia-Negron V, Motagamwala AH, Mellmer MA, Huang K (2017) Increasing the revenue from lignocellulosic biomass: Maximizing feedstock utilization. Sci Adv 3(5):e1603301

2. Anderson EL, Pawlak Z, Owen NL, Feist WC (1991) Infrared studies of wood weathering. Part I: Softwoods. Appl Spectrosc 45(4):641-647 
3. Bu L, Tang Y, Gao Y, Jian H, Jiang J (2011) Comparative characterization of milled wood lignin from furfural residues and corncob. Chem Eng J 175:176-184

4. Cao S, Aita GM (2013) Enzymatic hydrolysis and ethanol yields of combined surfactant and dilute ammonia treated sugarcane bagasse. Bioresour Technol 131:357-364

5. Castro E, Nieves IU, Mullinnix MT, Sagues WJ, Hoffman RW, Fernández-Sandoval MT, Tian Z, Rockwood DL, Tamang B, Ingram LO (2014) Optimization of dilute-phosphoric-acid steam pretreatment of Eucalyptus benthamii for biofuel production. Appl Energ 125:76-83

6. Chen C, Zhu H, Qin W, Chai L, Jia W (2018) Improving collecting performance of sodium oleate using a polyoxyethylene ether in scheelite flotation. J Cent South Univ 25(12):2971-2978

7. Chen H, Qiu W (2010) Key technologies for bioethanol production from lignocellulose. Biotechnol Adv 28(5):556-562

8. Chen Y, Sharma-Shivappa RR, Keshwani D, Chen C (2007) Potential of agricultural residues and hay for bioethanol production. Appl Biochem Biotechnol 142(3):276-290

9. Cheng B, Wang X, Lin Q, Zhang X, Meng L, Sun R-C, Xin F, Ren J (2018) New understandings of the relationship and initial formation mechanism for pseudo-lignin, humins, and acid-induced hydrothermal carbon. J Agric Food Chem 66(45):11981-11989

10. Chu Q, Chandra RP, Kim C-S, Saddler JN (2017) Alkali-oxygen impregnation prior to steam pretreating poplar wood chips enhances selective lignin modification and removal while maximizing carbohydrate recovery, cellulose accessibility, and enzymatic hydrolysis. ACS Sustain Chem Eng 5(5):4011-4017

11. Fockink DH, Sánchez JH, Ramos LP (2018) Comprehensive analysis of sugarcane bagasse steam explosion using autocatalysis and dilute acid hydrolysis ( $\mathrm{H} 3 \mathrm{PO} 4$ and $\mathrm{H} 2 \mathrm{SO} 4)$ at equivalent combined severity factors. Ind Crops Prod 123:563-572

12. Gao A, Shen H, Zhang H, Feng G, Xie K (2017) Hydrophilic modification of polyester fabric by synergetic effect of biological enzymolysis and non-ionic surfactant, and applications in cleaner production. J Clea Prod 164:277-287

13. Geddes CC, Mullinnix M, Nieves I, Peterson J, Hoffman R, York S, Yomano L, Miller E, Shanmugam K, Ingram $L$ (2011) Simplified process for ethanol production from sugarcane bagasse using hydrolysate-resistant Escherichia coli strain MM160. Bioresour Technol 102(3):2702-2711

14. Haldar D, Purkait MK (2020) A review on the environment-friendly emerging techniques for pretreatment of lignocellulosic biomass: Mechanistic insight and advancements. Chemosphere 264:128523

15. Haykiri-Acma H, Yaman S (2019) Effects of dilute phosphoric acid treatment on structure and burning characteristics of lignocellulosic biomass. J Energ Resour -ASME 141(8):082203

16. Ibrahim MM, Agblevor FA, El-Zawawy WK (2010) Isolation and characterization of cellulose and lignin from steam-exploded lignocellulosic biomass. BioResources 5(1):397-418

17. Jacquet N, Maniet G, Vanderghem C, Delvigne F, Richel A (2015) Application of steam explosion as pretreatment on lignocellulosic material: a review. Ind Eng Chem Res 54(10):2593-2598 
18. Jørgensen H, Kristensen JB, Felby C (2007) Enzymatic conversion of lignocellulose into fermentable sugars: challenges and opportunities. Biofuel Bioprod Bior 1(2):119-134

19. Kim TH (2011) Sequential hydrolysis of hemicellulose and lignin in lignocellulosic biomass by twostage percolation process using dilute sulfuric acid and ammonium hydroxide. Korean $\mathrm{J}$ Chem Eng 28(11):2156-2162

20. Koradiya M, Duggirala S, Tipre D, Dave S (2016) Pretreatment optimization of Sorghum pioneer biomass for bioethanol production and its scale-up. Bioresour Technol 199:142-147

21. Leu SY, Zhu J (2013) Substrate-related factors affecting enzymatic saccharification of lignocelluloses: our recent understanding. Bioenerg Res 6(2):405-415

22. Li H, Pu Y, Kumar R, Ragauskas AJ, Wyman CE (2014) Investigation of lignin deposition on cellulose during hydrothermal pretreatment, its effect on cellulose hydrolysis, and underlying mechanisms. Biotechnol Bioeng 111(3):485-492

23. Martín-Davison JS, Ballesteros M, Manzanares P, Sepúlveda XP-B, Vergara-Fernández A (2015) Effects of temperature on steam explosion pretreatment of poplar hybrids with different lignin contents in bioethanol production. Int J Green Energy 12(8):832-842

24. Nasirpour N, Mousavi S, Shojaosadati S (2014) A novel surfactant-assisted ionic liquid pretreatment of sugarcane bagasse for enhanced enzymatic hydrolysis. Bioresour Technol 169:33-37

25. Oliva JM, Negro MJ, Álvarez C, Manzanares P, Moreno AD (2020) Fermentation strategies for the efficient use of olive tree pruning biomass from a flexible biorefinery approach. Fuel 277:118171

26. Pitarelo AP, Fonseca CSd, Chiarello LM, Gírio FM, Ramos LP (2016) Ethanol production from sugarcane bagasse using phosphoric acid-catalyzed steam explosion. J Braz Chem Soc 27:18891898

27. Qi W, He C, Wang Q, Liu S, Yu Q, Wang W, Leksawasdi N, Wang C, Yuan Z (2018) Carbon-based solid acid pretreatment in corncob saccharification: specific xylose production and efficient enzymatic hydrolysis. ACS Sustain Chem Eng 6(3):3640-3648

28. Qing Q, Yang B, Wyman CE (2010) Impact of surfactants on pretreatment of corn stover. Bioresour Technol 101(15):5941-5951

29. Schwanninger M, Rodrigues J, Pereira H, Hinterstoisser B (2004) Effects of short-time vibratory ball milling on the shape of FT-IR spectra of wood and cellulose. Vib Spectrosc 36(1):23-40

30. Segal L, Creely JJ, Martin A Jr, Conrad C (1959) An empirical method for estimating the degree of crystallinity of native cellulose using the X-ray diffractometer. Text Res J 29(10):786-794

31. Shi GQ, Han C, Wang Y, Wang H-T (2019) Experimental study on synergistic wetting of a coal dust with dust suppressant compounded with noncationic surfactants and its mechanism analysis. Powder Technol 356:1077-1086

32. Singh J, Suhag M, Dhaka A (2015) Augmented digestion of lignocellulose by steam explosion, acid and alkaline pretreatment methods: a review. Carbohydr Polym 117:624-631 
33. Sluiter A, Hames B, Ruiz R, Scarlata C, Sluiter J, Templeton D, Crocker D (2008) Determination of structural carbohydrates and lignin in biomass. Lab Anal Proced 1617(1):1-16

34. Tu WC, Hallett JP (2019) Recent advances in the pretreatment of lignocellulosic biomass. Curr Opin Green Sust 20:11-17

35. Wang H, Liu Z, Zheng X, Pan X, Hui L, Li J, Zhang H (2020) Assessment on temperature-pressure severally controlled explosion pretreatment of poplar. Carbohydr Polym 230:115622

36. Yan J, Nie W, Xiu Z, Yuan M, Zhou W, Bao Q, Peng H, Niu W, Yu F (2021) Development and characterization of a dust suppression spray agent based on an adhesive NaAlg-glnpoly/polysaccharide polymer. Sci Total Environ 785:147192

37. Zeng J, Tong Z, Wang L, Zhu J, Ingram L (2014) Isolation and structural characterization of sugarcane bagasse lignin after dilute phosphoric acid plus steam explosion pretreatment and its effect on cellulose hydrolysis. Bioresour Technol 154:274-281

38. Zhang J, Tang M, Viikari L (2012) Xylans inhibit enzymatic hydrolysis of lignocellulosic materials by cellulases. Bioresour Technol 121:8-12

39. Zhang J, Zhou H, Liu D, Zhao X (2020) Pretreatment of lignocellulosic biomass for efficient enzymatic saccharification of cellulose. In P D Yousuf A, Sannino F (Ed) Lignocellulosic Biomass to Liquid Biofuels. Amsterdam, pp 17-65

40. Zheng T, Jiang J, Yao J (2020) Surfactant-promoted hydrolysis of lignocellulose for ethanol production. Fuel Process Technol 213:106660

41. Zhou H, Wang J, Han C, Yang B (1995) Preparation and application of penetrant JFC(M type). Jiangsu Silk 01:26 (In Chinese)

\section{Figures}
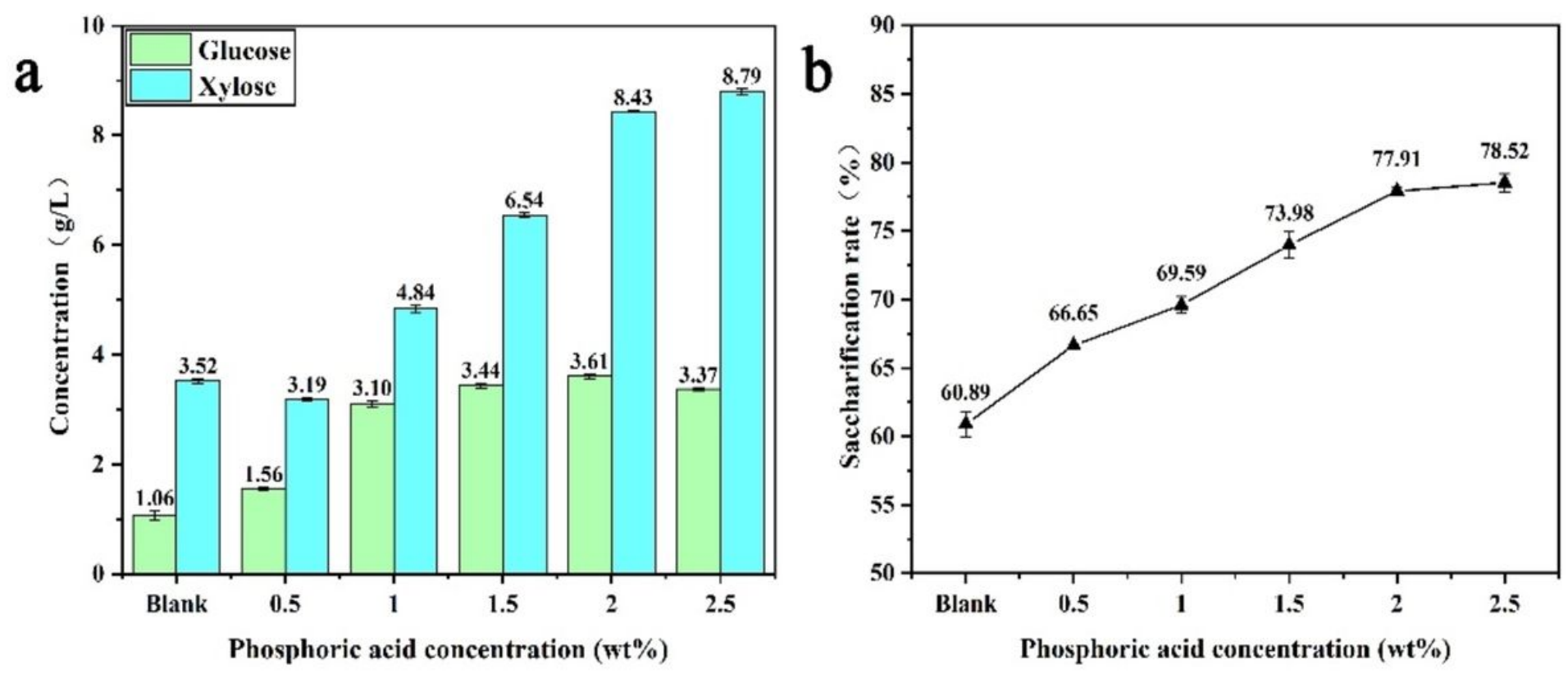
Figure 1

Effect of phosphoric acid on pretreatment. a: Yield of glucose and xylose in exploded filtrate;

b:Saccharification rate. Note:(1) Blank group: 2.0 wt\% H3PO4 + purified water; 0.5-2.5 wt\% H3PO4 groups: adding $2 \%$ (v/v) JFC-M. (2) SE parameters: 1:2.5 solid/liquid rate, $2 \mathrm{~h}$ pre-soaking time, 2.2 MPa SE pressure, $180 \mathrm{~s}$ SE residence time. (3) The contents of cellobiose and arabinose were below the detection limits.
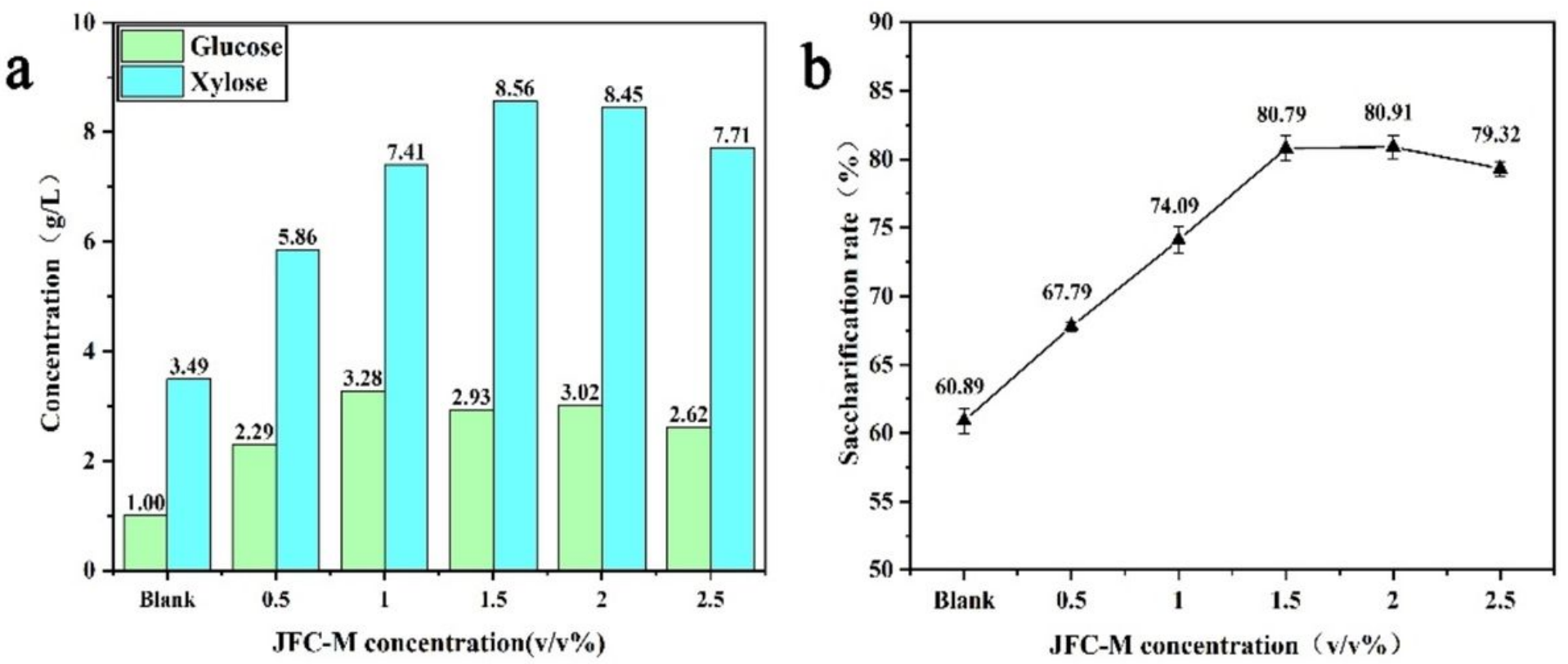

Figure 2

Effect of surfactant JFC-M on pretreatment.
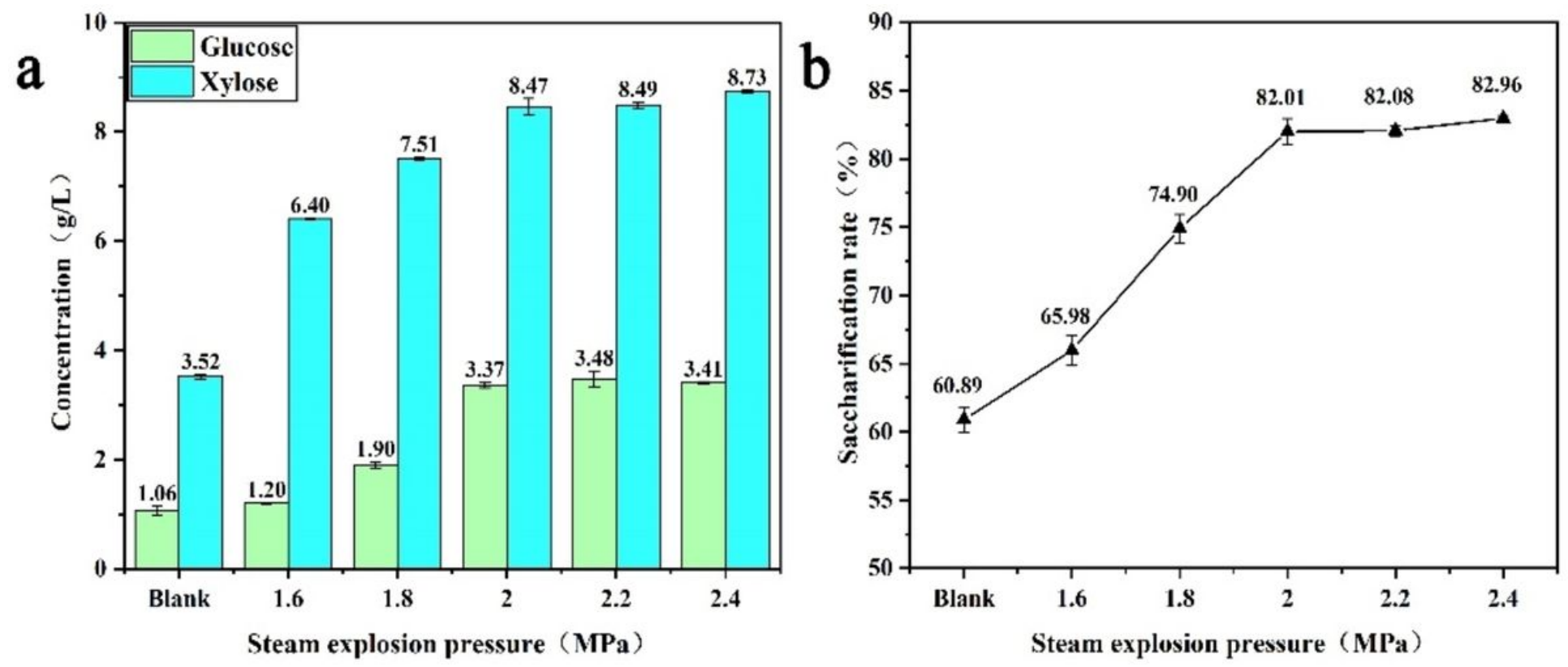

Figure 3 
Effect of pressure on pretreatment.
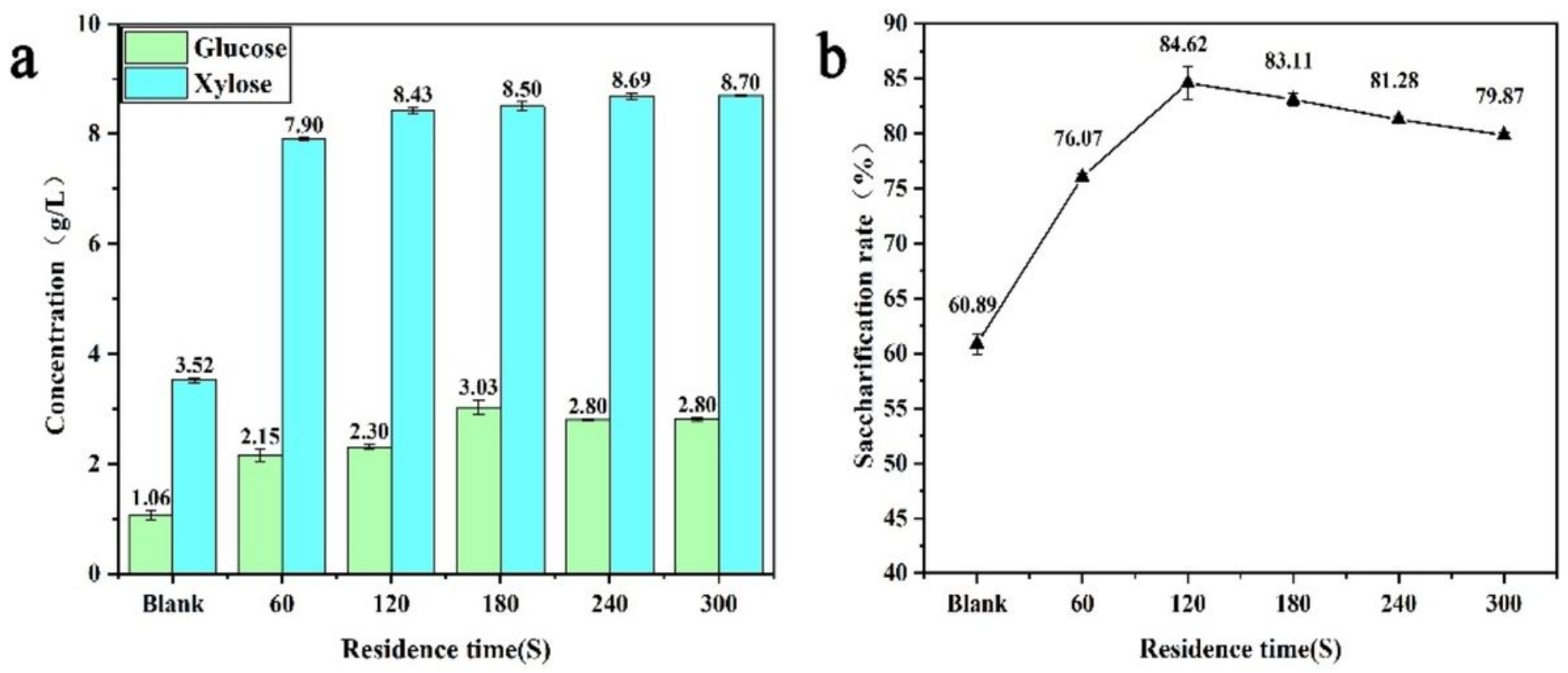

Figure 4

Effect of residence time on pretreatment. a: Yield of glucose and xylose in exploded filtrate; $b$ : Saccharification rate. Note:(1) Blank group: 2.0 wt\% H3PO4 + purified water;60-300 s residence time groups: adding $1.5(\mathrm{v} / \mathrm{v}) \% \mathrm{JFC}-\mathrm{M}+2.0 \mathrm{wt} \% \mathrm{H} 3 \mathrm{PO}$ 4. (2) SE parameters: 1:2.5 solid/liquid rate, $2 \mathrm{~h}$ presoaking time, 2.0 MPa SE pressure.
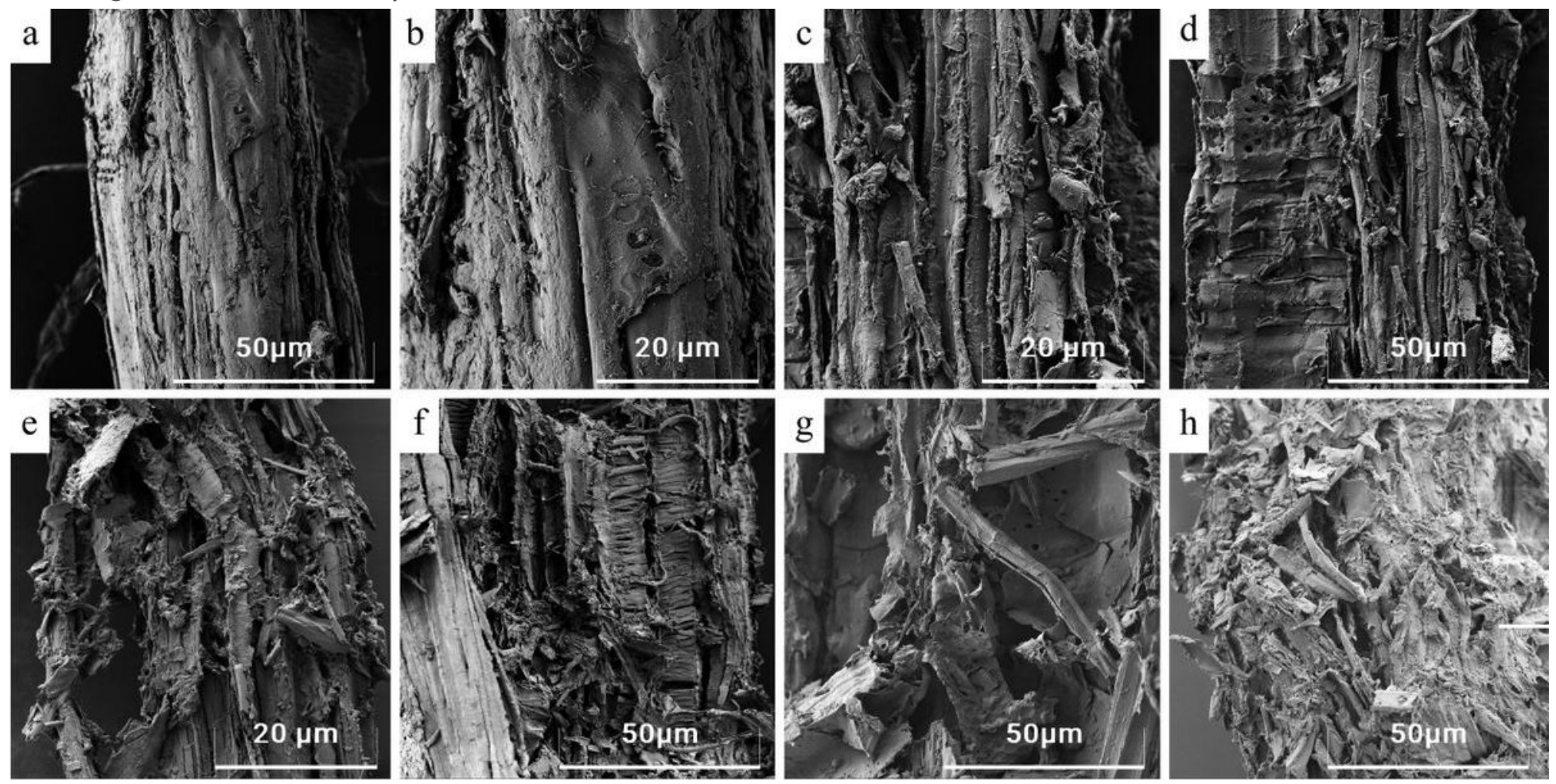

Figure 5

SEM images of samples before and after pretreatment. 


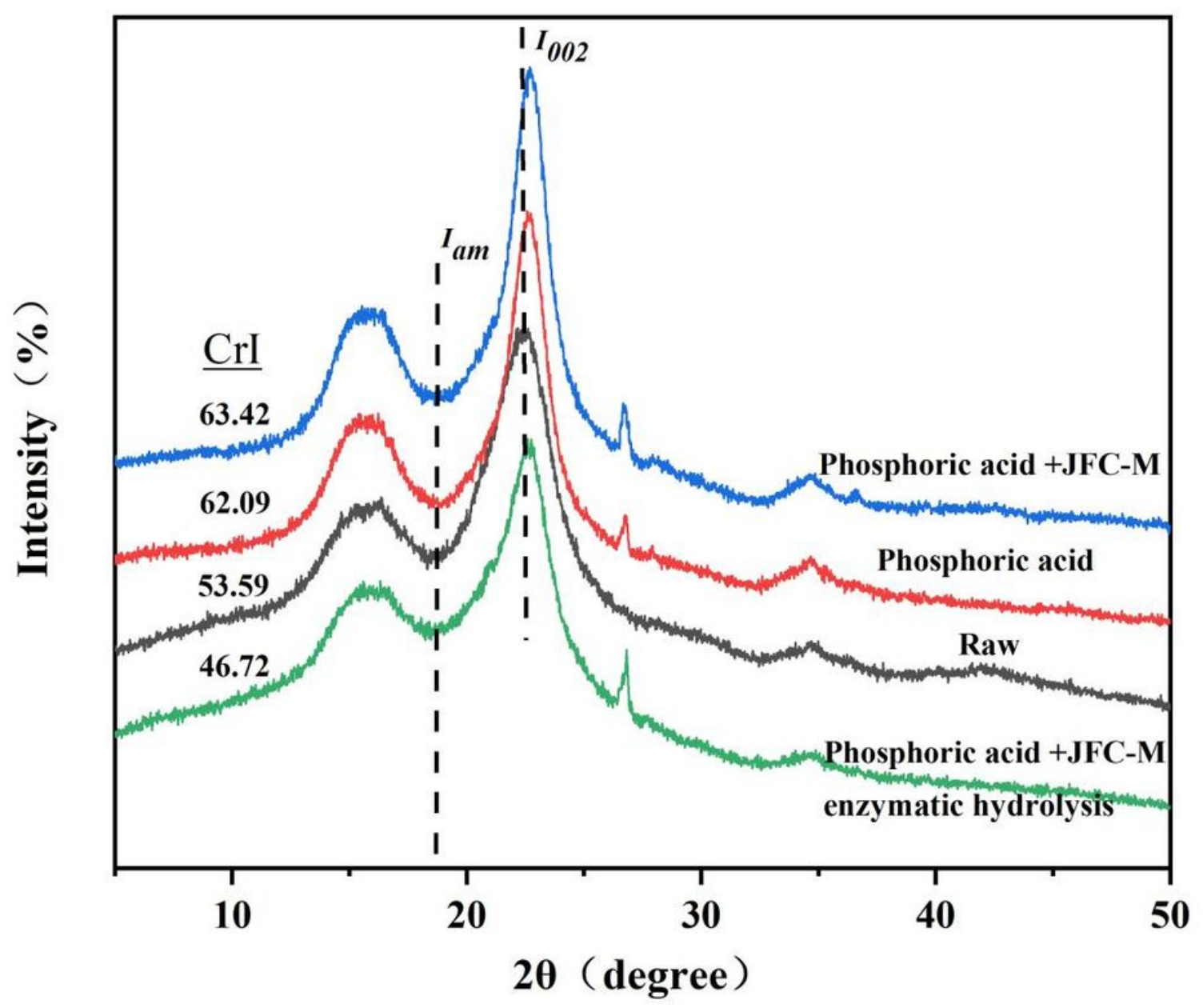

Figure 6

XRD patterns of samples. 


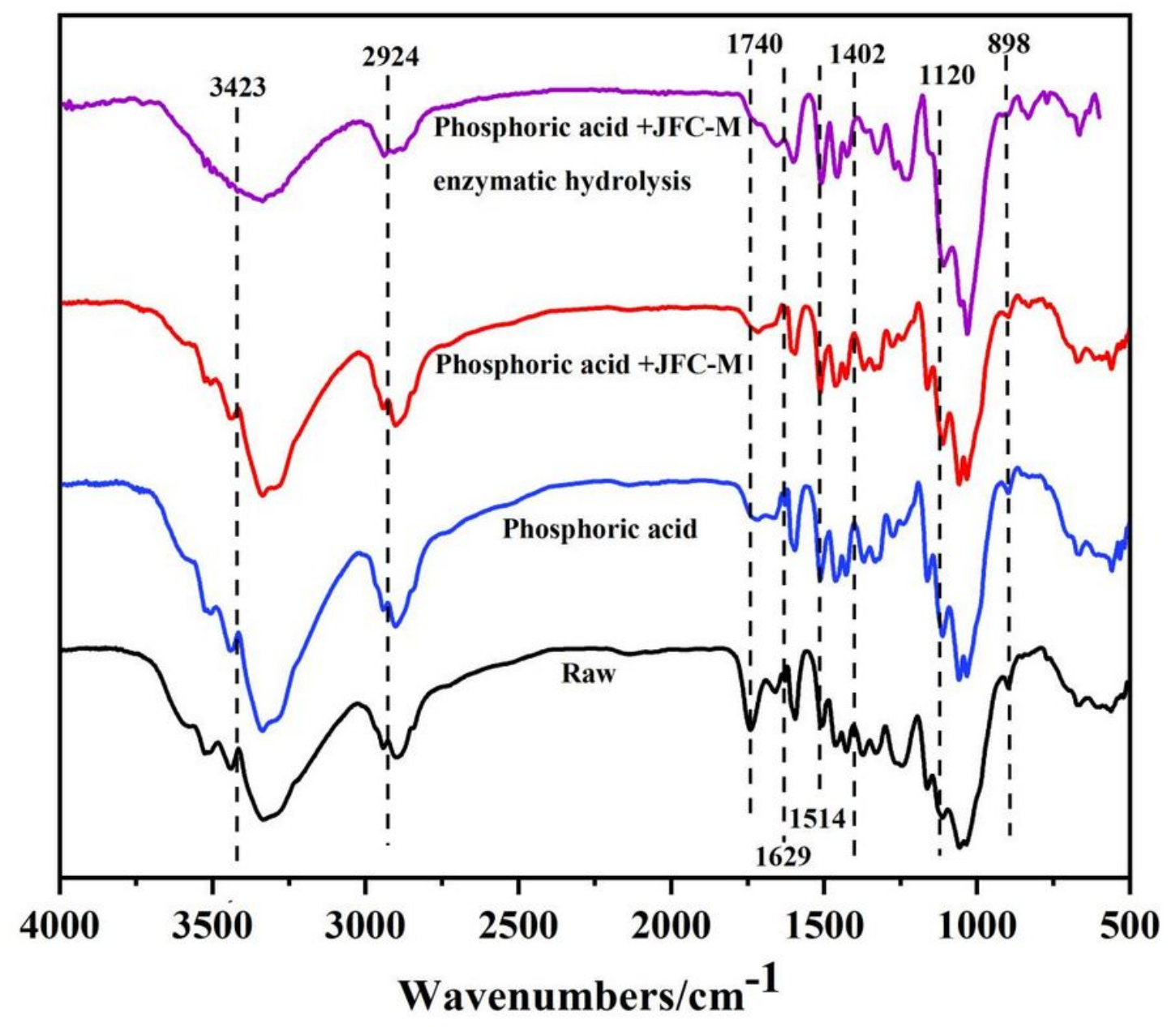

Figure 7

FTIR spectra of samples.

\section{Supplementary Files}

This is a list of supplementary files associated with this preprint. Click to download.

- GraphicalAbstract.png 